\title{
NUCLEAR MAGNETIC RESONANCE AS A DIAGNOSTIC TOOL IN BREAST CANCER
}

\author{
Hnilicova P., Dobrota D.
}

Department of Medical Biochemistry, Comenius University, Jessenius Faculty of Medicine, Mala Hora 4, 036 01, Martin, Slovakia

\begin{abstract}
The early detection and treatment of breast cancer is of direct benefit to patients. Magnetic resonance imaging (MRI) is a promising modality for detection, diagnosis, and staging of breast cancer. MRI enables two methods: the diffusion-weighted MRI (DW MRI) and the dynamic contrast enhanced MRI (DCE MRI). DW MRI reflects the diffusion of water molecules in the extracellular fluid space and allows the estimation of cellularity and tissue structure. The value of the diffusion of water in tissue is called the apparent diffusion coefficient (ADC). ADC values in malignant lesions are smaller than in benign tissue. DCE MRI yields appropriate pharmacokinetic data of physiological parameters that relate to tissue perfusion, microvascular vessel wall permeability and extracellular volume fraction. Gadolinium based contrast agent is usually used in breast DCE MRI diagnostics. Changes in the post-contrast signal intensity help to distinguish lesions according to characteristically enhanced accumulation of contrast agent. Malignant lesions are characterized by a faster and stronger signal enhancement than benign lesions which relate to their neoangiogenesis. Over the last few years, there has been appreciable interest in the use of magnetic resonance spectroscopy (MRS) for the non-invasive analysis of breast tisue metabolites. One of the spectroscopic hallmarks of the neoplastic process appears to be the presence of total choline signal in the in vivo spectrum. Despite the fact that MRI and MRS achieve excellent results, they are still not so frequently used in comparison to mammography and breast ultrasound.
\end{abstract}

Key words: magnetic resonance imaging, diffusion weighted MRI, dynamic contrast enhanced MRI, magnetic resonance spectroscopy, breast cancer.

\section{INTRODUCTION}

Breast cancer is a major cause of cancer-related deaths among women in most western countries $(1-4)$. According to recent statistics, the mortality and morbidity rates of breast cancer are the highest of all cancers in women in the Slovak Republic $(4,5)$. Therefore, early detection and treatment of breast cancer is necessary to patient survival.

\section{MAGNETIC RESONANCE IMAGING (MRI)}

The use of MRI as a diagnostic tool for detecting breast cancer began in the 1970s $(2,6)$. With the introduction of contrast agents, advances in surface coil technology, and development of new imaging protocols, MRI has emerged as a promising modality for detection, diagnosis, and staging of breast cancer (1, 6 - 9). MRI enables three investigative methods: the conventional MRI, the diffusion-weighted MRI (DW MRI), which aims at a meticulous analysis of the lesion's structure, and the dynamic contrast enhanced MRI (DCE MRI), which is based on tissue pharmacokinetic investigations $(8,10-12)$.

Address for correspondence:

Ing. Hnilicova Petra, Department of Medical Biochemistry, Jessenius Faculty of Medicine, Comenius University, Mala Hora 4, 03601 Martin, Slovak Republic

Phone: 043/2633407; e-mail: pet.hnilicova@gmail.com 


\section{DIFFUSION-WEIGHTED MRI (DW MRI)}

First proposed for the purposes of breast cancer detection in 1997, DW MRI has been suggested as a potential adjunct to the existing MR protocol in order to improve the overall specificity of breast MRI. DW MRI provides information on microstructure which has been shown to be an important index of tumor grade, and local tissue architecture, which is a sensitive early indicator of abnormality $(51,52)$.

DW MRI reflects the diffusion of water molecules in the extracellular fluid space and allows estimation of cellularity and tissue structure (48 - 55). DW MRI is based on random Brownian motion of molecules during the interval of excitation and signal measurement which reduces the amplitude of the resulting signal. The application of an appropriate pulse allows the measurement of the signal cancellation due to diffusion in a given direction. While normal tissue exhibits gross signal loss, areas with restricted motion of molecules like densely packed tumor cells show less signal loss and become bright in diffusion-weighted images (Figure 1).
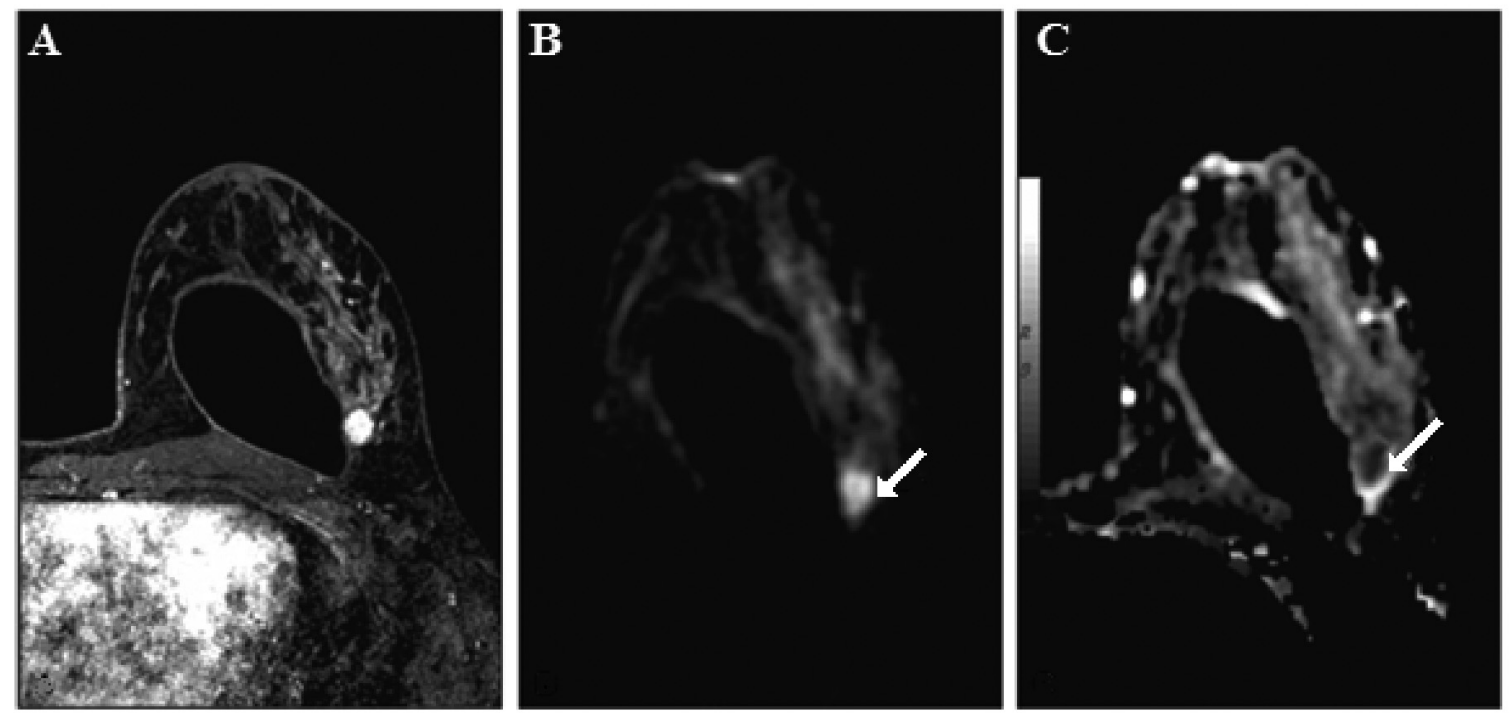

Fig. 1 Female, 48-year-old patient presenting infiltrating ductal carcinoma in the left breast. Axial, 3D gradient $\mathrm{T}_{1}$-weighted sequence with fat-suppression at early postcontrast phase (A), diffusion-weighted sequence $\left(b=500 \mathrm{~s} / \mathrm{mm}^{2}\right)$ in the axial plane (B), and apparent diffusion coefficient (ADC) black / white map in the axial plane (C) show microlobulated nodule with suspicious contrast-enhancement. Note that the nodule presents high signal intensity on the diffusion (arrow) and signal loss on the ADC map (arrow), suggesting restricted diffusion of water molecules (55)

The value of the diffusion of water in tissue is called the apparent diffusion coefficient (ADC). Based on the diffusion-weighted images an ADC map can be calculated which shows the $\mathrm{ADC}$ value of each voxel in every slice. Restricted water movement in tumors with high cellularity leads to smaller ADC values than in benign tissue. This is likely to be caused by increased cellularity, larger nuclei, and less extracellular space. Furthermore, in malignant tumors, a higher percentage of microvessels is present than in benign tissue. Perfusion may, therefore, artificially increase ADC in malignant lesions and hinder differentiation $(44,46$ - 48, 51, 53, 54, 55).

However, in tumor clusters the diffusion is vastly restricted in every direction and therefore it is sufficient to measure DWI of the breast in just one orientation. In most 
applications the diffusion gradients are integrated in echo planar imaging (EPI) sequences which exhibit high signal intensity in areas with restricted diffusion as well as in fatty tissue. Furthermore, the fat signal is displaced in the direction of the chemical shift as compared to the water signal. This makes fat saturation techniques necessary to identify the lesions in the diffusion-weighted images $(44,47-49)$.

Image interpretation starts like conventional breast MRI. If a lesion is visualized in the dynamic scan it has to be identified in the corresponding slice of the diffusionweighted images. As a second step, a region-of-interest (ROI) is drawn in the centre of the lesion and copied to the ADC map. The scanner software provides the mean value within the $\mathrm{ROI}$ which equals the $\mathrm{ADC}$ value. The $\mathrm{ADC}$ in each voxel is a sum of the true $\mathrm{ADC}$ and noise. To estimate the true $\mathrm{ADC}$, the noise must be minimized. This is especially important for small lesions, where the accurate determination of the mean ADC relies on only a few voxels. The precision of $\mathrm{ADC}$ determination reaches a maximum at a $b$ value, which is a scan parameter. The $b$ factor depends on target organs, lesions, and equipment. The optimum $b$ factor should sufficiently suppress the background signal of the mammary gland and provide a cancer signal that is strong enough to allow image interpretation. Previous studies have suggested that the optimal $b$ value for breast lesion classification with DW MRI is between 700 and 1000. However, it is also well known that higher $b$ values result in reduced signal to noise ratio (SNR) and therefore lower image quality. If the lesion is not visible in the $b 800$ images, the location of the lesion can be identified at least $b$ in the 50 image, otherwise the ADC value can not be evaluated $(44,47,50,51,53,55)$. Lesions smaller than $5 \mathrm{~mm}$ and lesions with central necrosis and an enhancing rim smaller than $5 \mathrm{~mm}$ are often harder to delineate in the DWI or lead to wrong ADC values $(44,47)$. Application of DW MRI to the breast has been limited by movement artifacts such as breathing and heartbeats $(49,52,55)$.

\section{DYNAMIC CONTRAST ENHANCED MRI (DCE MRI)}

DCE MRI yields appropriate pharmacokinetic data of physiological parameters that relate to tissue perfusion, microvascular vessel wall permeability and extracellular volume fraction $(9,12$ - 15). DCE MRI, on the other hand, is a technological process in which serial $\mathrm{T}_{1}$ - weighted $3 \mathrm{D}$ MR images of both breasts are acquired before and repetitively after the administration of the contrast agent. This agent, usually gadolinium based, is a paramagnetic substance which generates its own magnetic field. This magnetic field decreases relaxation times $\left(\mathrm{T}_{1}, \mathrm{~T}_{2}\right)$ and so enables differences between tissues according to the volume of contrast agent $(9,10,11,14,16)$. Gadolinium - diethylenetriamine pentaacetic acid (Gd - DTPA) contrast agent is commonly used in breast DCE MRI $(10,11)$. The first to apply Gd - DTPA as a contrast agent in breast MRI was Heywang et al. in 1985. Following that in 1989 Kaiser et al. first reported dynamic breast MRI, as a modality designed to track rapid changes in signal intensity $(7,14,24)$. Changes in the post-contrast signal intensity helped to distinguish lesions according to characteristic enhanced accumulation of contrast agent could then be related to higher tissue microvascularity $(1,7,12,13,15,17,18)$. Tumor growth is dependent on angiogenesis, which provides the tumor with nutrients. Therefore, the microvessel density is much higher in cancers than in healthy tissue $(9,14-16,19)$. Malignant lesions are characterized by a faster and stronger signal enhancement than benign lesions which relate to their neoangiogenesis. However, benign lesions may also show rapid enhancement during strong hormonal stimulation (e.g., pregnancy, oral contraception, fibroadenomas) $(6,9,10,14,15,17$ - 20).

Subsequently, a small ROI is drawn over the region that appears to be the most enhancing in the lesion and the enhancement values at different pre-and post-contrast time points are calculated over this to form the kinetic curve (Figure 
2) $(7,8,10,11,20,21)$. With the use of dynamic data sets, two different criteria may ensue to describe lesion enhancement kinetics:

1. The first is to analyse the behaviour of signal intensity in the early phase after the administration of contrast material. It is evaluated by means of the steepness of the postcontrast signal intensity curve. Several descriptors are applied to this criterion: curve slope, early-phase enhancement rate, enhancement velocity, or percentage of increase in signal intensity. The largest increase in relative signal intensity which usually occurs in the first postcontrast minute is referred to as the enhancement or wash-in rate. The malignant lesions tend to have higher enhancement velocities than benign ones $(1,7,11)$.

2. A more common practice, as a modality for any cancer detection is to observe the signal intensity behaviour in intermediate and late post-contrast phases of the DCE MRI curves $(7,8,9,22)$. The late post-contrast phases of the DCE MRI curves depend on their shapes and are categorized into three types as shown below in Figure $3(7,8,10,11,13,21)$ :

* Type I, a persistent curve with continuous increase in enhancement for benign lesions,

* Type II, a plateau curve that reaches a maximum signal intensity approximately 2 to 3 min after contrast agent injection. The signal intensity remains constant after reaching the maximum because of saturation effects. A plateau curve can be seen with both benign and malignant lesions.

* Type III, a washout curve with decreasing signal intensity after peak enhancement for malignant lesion;

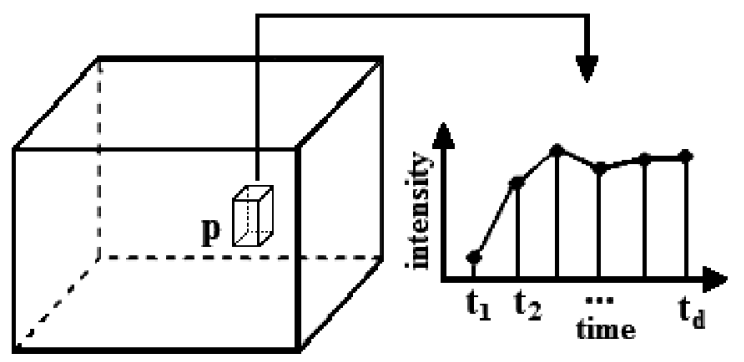

Fig. 2 The principle of creating kinetic DCE MRI curves (21)

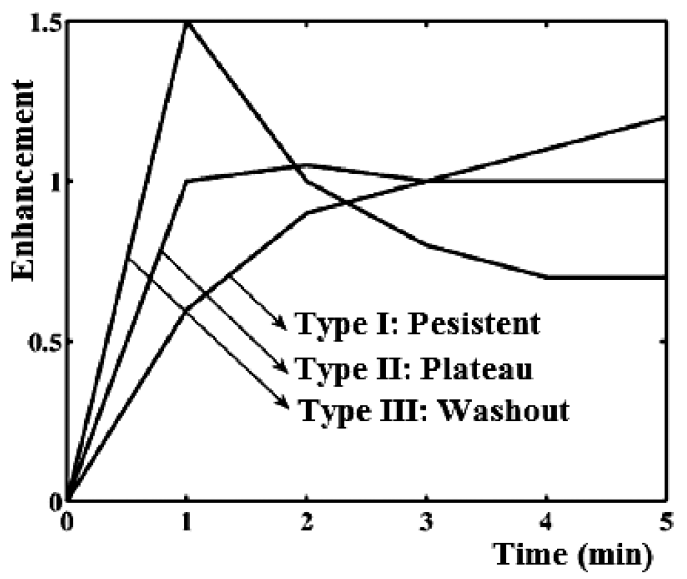

Fig. 3 The three types of kinetic DCE MRI curves; type I: a persistent curve for benign lesions, type II: a plateau curve for both types of lesions, type III: a wash out curve for malignant lesions (10) 
A breast tumor leads to angiogenesis, i.e. the formation of new vessels and/or the sprouting of existing capillaries. These newly formed vessels yield an early contrast agent enhancement, and therefore, a strong contrast agent washin. Furthermore, the vessels, as a result of the angionetic activity of the tumor, become highly permeable and a rapid contrast agent washout would then be expected in tumorous tissue $(2,9,14-16,19)$. In many cases, the targeted tumor is very heterogeneous and the most appropriate part of it then is not so easily determined. To avoid the distortion of the average time-intensity curve, the ROI should be very small and must not include dead tumor cells (necrosis) or surrounding tissue. The heterogeneity of tumor vascularization, the proximity of necrotic and vital tumor tissue, and the subjectiveness of ROI placement complicate the interpretation of the kinetics and may even result in unrevealed malignant tissue. This could happen, if an ROI covers malignant and benign tissue, with an average curve shape indicating benignity $(2,7,8,10)$. Whereas it is still not standardized the method for generating kinetic curves is accepted as both inter-and intraobserver variability $(7,8,10,11,20,21)$. In general, though, DCE MRI has excellent sensitivity despite its variable specificity for breast cancer detection $(10,14,15,22,24)$.

\section{MAGNETIC RESONANCE SPECTROSCOPY (MRS)}

Over the last few years, there has been appreciable interest in the use of proton magnetic resonance spectroscopy for the non-invasive diagnosis of breast lesions. The normal breast consists of glandular and adipose tissue, which in the proton spectrum exhibit large signals from water $(4.7 \mathrm{ppm})$ and lipid resonances (multiple lipid resonances: at 0.9 and $1.3 \mathrm{ppm}$, at 2.2 and $2.5 \mathrm{ppm}$, at $5.2 \mathrm{ppm}$ ). When water and lipid suppression pulses are turned on, it becomes possible to observe much smaller metabolite signals: various compounds including choline $(\mathrm{Cho}, 3.2 \mathrm{ppm})$, creatine $(\mathrm{Cr}$, 3.0 and $3.9 \mathrm{ppm}$ ), taurine (Tau, $3.3 \mathrm{ppm}$ ), glycine (Gly, $3.5 \mathrm{ppm}$ ), and alanine (Ala, 3.8 ppm), amongst others $(27,28,38,39,43)$. It should be noted that these signals are generally only clearly observed using high-strength magnetic fields (at least $4 \mathrm{~T}$ ) and state-of-the-art methodology. Using lower field strength $(1.5 \mathrm{~T})$ systems, the only observable signals, in the normal breast tissue, may be residual water and lipids. One

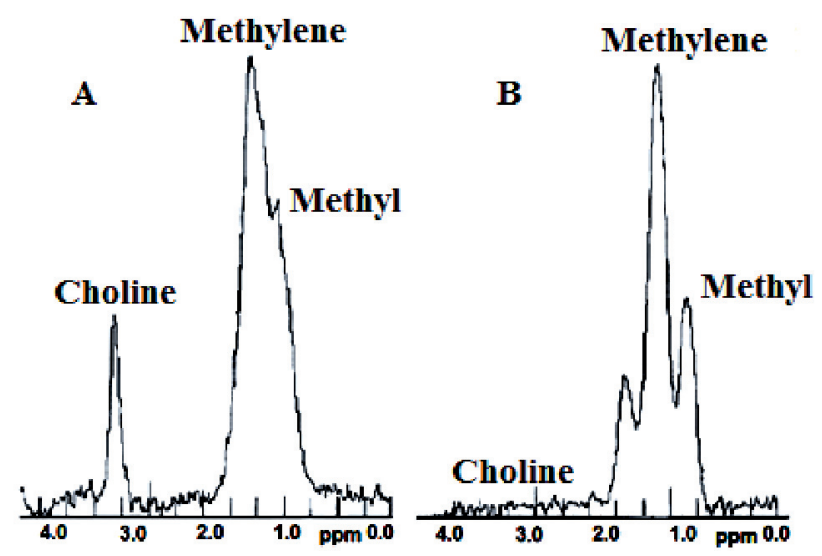

Fig. 4 Localized proton spectra from the human breast recorded using the PRESS pulse sequence (1.5 T, TR $2 \mathrm{sec}$, TE $350 \mathrm{msec}, 256$ averages, $3.8 \mathrm{~cm}^{3}$ voxel size).

(A) Infiltrating ductal carcinoma, (B) fibroadenoma. Lipid methyl and methylene signals are observed in both spectra, while an elevated choline peak at $3.2 \mathrm{ppm}$ is only detected in the carcinoma (A) (27) 
of the spectroscopic hallmarks of the neoplastic process appears to be the presence of a choline signal in the in vivo spectrum, predominantly consisting of phosphocholine (PC), glycerophosphocholine (GPC), and some free choline itself usually in higher concentrations than in normal tissue or in non-malignant lesions (Figure 4). However, the precise mechanisms that produce an elevated total choline (tCho) concentration have not yet been fully identified. A working hypothesis is that elevated tCho is an indicator of increased cellular proliferation. The largest component contributing to the tCho peak from neoplastic tissue is phosphocholine, a known precursor of membranes. Thus, the increased tCho in neoplastic tissues may be a reflection of increased membrane turnover by replicating cells $(27,29,30,37$ - 39, 43). Normal tissue, and many firoadenomas, should not exceed a Cho concentration of $1 \mathrm{mmol}^{\mathrm{kg}} \mathrm{kg}^{-1}$, so a concentration higher than this value is suspicious for malignancy. However, this may not be the case under all circumstances; for instance, it has been reported that Cho and lactose signals $(\sim 3.8 \mathrm{ppm})$ can be observed in women who are lactating $(27,37,39)$.

MRS may also be used to determine if a tumor is responding to a particular chemotherapy regime. It has been hypothesized that biochemical measurements of tumor Cho will decrease as cells are killed, prior to reduction in tumor size. An earlier indicator of tumor response could in principle be used to alter chemotherapeutic agent or dosage, rather than performing several weeks of ineffective therapy $(27,38-40)$.

Various factors, as listed below, should be kept in mind when evaluating spectra from breast lesions $(27,31,32,37,39)$ :

* Lesion size: Since the signal-to-noise ratio (SNR) of a spectrum depends linearly on the voxel size (amongst other factors), smaller lesions will be less likely to show detectable tCho signal than larger ones. Limitation of lesions is $2 \mathrm{~cm}^{3}$ or larger at $1.5 \mathrm{~T}$.

* SNR: It should also be kept in mind that, under high SNR conditions, it is possible to detect tCho signal from normal fibroglandular tissue. Spectral resolution and SNR are critically dependent on magnetic field homogeneity, which can be challenging to optimize in the breast, even at field strengths of $1.5 \mathrm{~T}$.

* Field homogeneity: For better homogeneity sensitive phased-array receiver coils should be used. Breast and respiratory motions are undesirable under these circumstances.

* Suppresion of water and lipids: It has been shown that small magnetic field instabilities can modulate the large lipid signals typically found in the breast to produce discrete sidebands, which can overlap with or mimic small Cho signals.

\section{CONCLUSION}

After establishing the existence of a lesion in breast, it is critical to determine whether this lesion is benign or malignant. The sensitivity of breast cancer detection by mammography is $69 \%-90 \%$. It has been estimated that between $5 \%$ and $15 \%$ of tumors are missed. Sonographic classification of benign and malignant tumors is of a low specificity as well-approximately $30 \%(6,27,37,45-49)$.

MRI has been the most commonly used modality due to its wide availability and lack of ionizing radiation (20). Due to increased vascularity and capillary permeability of tumors, DCE MRI shows better distinction between lesions and normal tissue than conventional MRI alone (1). Despite the fact that MRI and MRS achieve excellent results, they are still not so frequently used in comparison to mammography and breast ultrasound. From current consensus, NMR is particularly suited for specific cases, such as patients who have undergone breast-conserving therapy, patients who have high risk of developing breast cancer, patients with implants, plus, postoperative scars, or clinical evidence of breast cancer that can not be detected by other diagnostic me- 
thods $(1,6,10$ - 12, 15, 22, 24). Breast MR imaging may improve detection of localized breast cancer by revealing multifocal growth in patients scheduled for conservative breast surgery $(9,11,12,22)$. In general, the sensitivity reported for diagnosis of breast cancer using MRI is larger than $90 \%$, but the reported specificity varies considerably and may be substantially lower (1). The sensitivity of breast DCE MRI has been reported to range from $90 \%$ to $100 \%$ for the detection of breast cancer, whereas the specificity has been reported to be between $20 \%$ and $90 \%$, which is likely to be lower than the sensitivity $(3,6,8,26,27,52)$. DW MRI is the only method to measure molecular diffusion in vivo. Furtheremore, it provides extensive information without contrast medium. An ADC threshold level between malignant and benign lesions with a diagnostic accuracy is around $95 \%(49,52,53)$.

MRI s main disadvantages are: it has a long scan time and it is a relatively expensive examination. The use of contrast agent is contraindicated in patients with a high risk of nephrogenic systemic fibrosis. The Committee for Medicinal Products for Human Use (CHMP) does not recommend their use in the following cases $(10,15,25)$ :

* in patients with kidney problems and patients receiving a liver transplant,

* in neonates and infants,

* in the elderly,

* in pregnant or breastfeeding women.

It is still valuable to add additional modalities which could increase diagnostic confidence. Magnetic resonance spectroscopy has the potential to fulfil this role. Furthermore, MRS is low-risk in that it is non-invasive, and does not involve radiation. It can also be cost-effective and useful in radiographically dense breasts. ${ }^{1} \mathrm{H}$ MRS of the breast has a sensitivity of $70 \%-96 \%$ and a specificity of $83 \%-93 \%$ for the detection of breast cancer $(37,38,41-43)$. Nevertheless, at present it largely remains mainly an experimental procedure $(27,33-37)$.

\section{REFERENCES}

1. Gilhujs KGA, Gigeret ML, Bick U. Computerized analysis of breast lesions in three dimensions using dynamic magnetic-resonance imaging. Med.Phys.1998; 25: 1647-1654.

2. Glaßer S, Preim U, Tönnies K, Preim B. A visual analytics approach to diagnosis of breast DCE-MRI data. Computers \& Graphics 2010; 34: 602 - 611.

3. Nishiura M, Yasuhiro T, Murase K. Evaluation of time-intensity curves in ductal carcinoma in situ (DCIS) and mastopathy obtained using dynamic contrast enhanced magnetic resonance imaging. Magnetic Resonance Imaging 2011; 29: 99-105.

4. Bella V. Stav skríningu karcinómu prsníka a dalšie možnosti rozvoja. Onkológia 2006; 1: 26-28.

5. Hlava P, Obšitníková A, Pleško I, Baráková A, Diba ChS. Zhubné nádory v SR - vybrané epidemiologické ukazovatele. Odbor národných zdravotných registrov, Národné centrum zdravotníckych informácií 2010

6. Orel SG, Schnall MD, LiVolsi VA, Troupin RH. Suspicious breast lesions: MR imaging with radiologicpathologic correlation. Radiology 1994; 190: 485-493.

7. Tozaki M. Interpretation of breast MRI: correlation of kinetic and morphological parameters with pathological findings. Magnetic resonance in Medical Sciences 2004; 3: 189-197.

8. Orel SG, Schnall MD. MR Imaging of the Breast for the Detection, Diagnosis, and Staging of Breast Cancer. Radiology 2001; 220:13-30.

9. Kurz KD, Roy S, Mödder U, Skaane P, Saleh A. Typical atypical findings on dynamic MRI of the breast. European Journal of Radiology 2010; 76: 195-210.

10. Chen W, Gigeret ML, Bickal U, Newstead GM. Automatic identification and classification of characteristic kinetic curves of breast lesions on DCE-MRI. Medical Physics 2006; 33: 2878 - 2887.

11. Kuhl ChK, Mielcareck P, Klaschik S, Leutner C, Wardelmann E, Gieseke J, Schild HH. Dynamic breast MR imaging: are signal intensity time course data useful for defferential diagnosis of enhancing lesions? Radiology 1999; 211: 101-110.

12. Yankeelov TE, Lepage M, Chakravarthy A, Broome EE, Niermann KJ, Kelley MC, Meszoely I, Mayer IA, Herman ChR, McManus K, Price RR, Gore JC. Integration of quantitative DCE-MRI and ADC mapping to monitor treatment response in human breast cancer: initial results. Magnetic Resonance Imaging 2007; $25: 1$ 1-13.

13. Sinha S, Lucas-Quesada FA, Sinha U, DeBruhl N, Bassett LW. In Vivo Diffusion-Weighted MRI of the Breast: Potential for Lesion Characterization. Journal of magnetic resonance imaging 2002; 15: 693-704. 
14. Galiè M, Farace P, Merigo F, Fiorini S, Tambalo S, Nicolato E, Sbarbati A, Marzola P. Washout of small molecular contrast agent in carcinoma-derived experimental tumors. Microvascular Research 2009; 78: 370-378.

15. Lehotská V. Význam a možnosti magnetickej rezonancie (MR-MAMOGRAFIE) v diagnostike prsníkových lézií. Onkológia 2007; 4: $211-214$.

16. Castellani U, Cristani M, Daducci A, Farace P, Marzola P, Murino V, Sbarbati A. DCE-MRI data analysis for cancer area classification. Methods Inf Med 2009; 3: 248-253.

17. American College of Radiology. Breast imagng reporting and gata system 2011 (URL: http://www.birads.at/info.html)

18. Lucht REA, Delorme S, Heiß J, Knopp MV, Weber MA, Griebel J, Brix G. Classification of Signal-Time Curves Obtained by Dynamic Magnetic Resonance Mammography. Statistical Comparison of Quantitative Methods. Invest Radiol 2005; 40: 442-447.

19. Fox SB, Generali DG, Harris AL. Breast tumour angiogenesis. Breast Cancer Research 2007; 10: 11861796.

20. Jackson A, O'Connor JPB, Parker GJM, Jayson GC. Imaging tumor vascular heterogeneity and angiogenesis using dynamic contrast enhanced magnetic resonance imaging. Clin Cancer Res 2007; 13: 34493459.

21. Twellmann T, Saalbach A, Gerstung O, Leach MO, Nattkemper TW. Image fusion for dynamic contrast enhanced magnetic resonance imaging. BioMedical Engineering OnLine 2004; 35: 1-21.

22. Elmore JG, Armstrong K, Lehman CD, Fletcher SW. Screening for Breast Cancer. JAMA 2005; 293: 12451256.

23. Xinapse Systems Ltd. 2011 (URL: http://www.xinapse.com/ )

24. Siegmann KC, Schimpfle MM, Schick F, Remy ChT, Fersis N, Ruck P, Gorriz C, Claussen CD. MR Imaging-Detected Breast Lesions: Histopathologic Correlation of Lesion Characteristics and Signal Intensity Data. AJR 2002; 178: 1403-1409.

25. European Medicines Agency (EMEA). Questions and answers on the review of gadolinium-containing contrast agents. 2009 (URL: http://www.emea.europa.eu).

26. Morris E. Review of breastMRI: indications and limitations. In: MillerW. editor. Seminars in roentgenology. Philadelphia (Pa): Saunders 2001; 226 - 37.

27. Barker PB, Bizzi A, Stefano ND, Gullapalli RP, Lin DDN. MRS in breast cancer. In: Clinical MR Spectroscopy, Techniques and Applications. 1st ed. New York: United States of America by Cambridge University Press; 2010. p. 229-242.

28. Haddadin IS, Mcintosh A, Meisamy S, Corum C, Snyder AL, Powell NJ, et al. Metabolite quantification and high-field MRS in breast cancer. NMR Biomed 2009; 22: 65-76.

29. Sitter B, Sonnewald U, Spraul M, Fjosne HE, Gribbestad IS. High-resolution magic angle spinning MRS of breast cancer tissue. NMR Biomed 2002; 15: 327-37.

30. Barker PB, Breiter SN, Soher BJ, Chatham JC, Forder JR, Samphilipo MA, et al. Quantitative proton spectroscopy of canine brain: In vivo and in vitro correlations. Magn Reson Med 1994; 32 : $157-63$.

31. Bolan PJ, Delabarre L, Baker EH, Merkle H, Everson LI, Yee D, et al. Eliminating spurious lipid sidebands in 1 H MRS of breast lesions. Magn Reson Med 2002; 48:215-22.

32. Hoult DI, Richards RE. The signal-to-noise ratio of the nuclear magnetic resonance experiment. J Magn Reson 1976; 24: 71-85.

33. Meisamy S, Bolan PJ, Baker EH, Pollema MG, Le CT, Kelcz F, et al. Adding in vivo quantitative $1 \mathrm{H}$ MR spectroscopy to improve diagnostic accuracy of breast MR imaging: Preliminary results of observer performance study at 4.0 T. Radiology 2005; 236: 465-75.

34. Jacobs MA, Barker PB, Argani P, Ouwerkerk R, Bhujwalla ZM, Bluemke DA. Combined dynamic contrast enhanced breast MR and proton spectroscopic imaging: A feasibility study. J Magn Reson Imaging 2005; 21: 23-8.

35. Jacobs MA, Barker PB, Bluemke DA, Maranto C, Arnold C, Herskovits EH, et al. Benign and malignant breast lesions: Diagnosis with multiparametric MR imaging. Radiology 2003; 229: 225-32.

36. Jacobs MA, Ouwerkerk R, Wolff AC, Stearns V, Bottomley PA, Barker PB, et al. Multiparametric and multinuclear magnetic resonance imaging of human breast cancer: Current applications. Technol Cancer Res Treat 2004; 3: 543-50.

37. Katz-Brull R, Lavin PT, Lenkinski RE. Clinical Utility of Proton Magnetic Resonance Spectroscopy in Characterizing Breast Lesions. Journal of the National Cancer Institute 2001; 94:1197- 1203.

38. Cecil KM, Schnall MD, Siegelman ES, Lenkinski RE. The evaluation of human breast lesions with magnetic resonance imaging and proton magnetic resonance spectroscopy. Breast Cancer Res Treat 2001; 68: 45-54.

39. Kvistad KA, Bakken IJ, Gribbestad IS, Ehrnholm B, Lundgren S, Fjosne HE, et al. Characterization of neoplastic and normal human breast tissues with in vivo (1)H MR spectroscopy. J Magn Reson Imaging 1999; 10:159-64.

40. Jagannathan NR, Kumar M, Seenu V, Coshic O, Dwivedi SN, Julka PK, et al. Evaluation of total choline from in-vivo volume localized proton MR spectroscopy and its response to neoadjuvant chemotherapy in locally advanced breast cancer. Br J Cancer 2001;84:1016-1022. 
41. Roebuck JR, Cecil KM, Schnall MD, Lenkinski RE. Human breast lesions: characterization with proton MR spectroscopy. Radiology 1998;209:269-75.

42. Yeung DK, Cheung HS, Tse GM. Human breast lesions: Characterization with contrast-enhanced in vivo proton MR spectroscopy - initial results. Radiology 2001;220:40-6.

43. Bolan PJ, Nelson MT, Yee D, Garwood M. Imaging in breast cancer: Magnetic resonance spectroscopy. Breast Cancer Research 2005; 7:149-152.

44. Wenkel E, Geppert Che, Uder M, Kiefer B, Bautz W, Janka R. Diffusion-Weighted Imaging in Breast MRI - An Easy Way to Improve Specificity. MAGNETOM Flash 2007; 3: 28-32.

45. Buchberger W, Niehoff A, Obrist P, DeKoekkoek-Doll P, Dunser M. Clinically and mammographically occult breast lesions: detection and classification with high-resolution sonography. Semin Ultrasound CT MR 2000; 21: 325-36.

46. Guo Y, Cai YQ, Cai ZL, et al. Differentiation of clinically benign and malignant breast lesions using diffusion-weighted imaging. J Magn Reson Imaging 2002; 16:172-178.

47. Nass S, Henderson I, Lashof J, et al. Mammography and Beyond: Developing Technologies for the Early Detection of Breast Cancer. Washington, DC: Institute of Medicine, National Academy Press, 2001.

48. Sinha S, Lucas-Quesada FA, Sinha U, DeBruhl N, Bassett LW. In Vivo Diffusion-Weighted MRI of the Breast: Potential for Lesion Characterization. J. Magn. Reson. Imaging 2002; 15: 693-704.

49. Yoshikawa MI, Ohsumi S, Sugata S, Kataoka M, Takashima S, Kikuchi K, Mochizuki T. Comparison of breast cancer detection by diffusion-weighted magnetic resonance imaging and mammography. Radiat Med 2007; 25:218-223.

50. Kuroki Y, Nasu N. Advances in breast MRI: diffusion-weighted imaging of the breast. Breast Cancer 2008; 15: 212-217.

51. McClymont D, Mehnert A, Trakic A, Crozier S, Kennedy D. Improving the Discrimination of Benign and Malignant Breast MRI Lesions using the Apparent Diffusion Coefficient. Digital Image Computing: Techniques and Applications 2010; 569-574.

52. Yoshikawa MI, Ohsumi S, Sugata S, Kataoka M, Takashima S, Mochizuki T, Ikura H, Imai Y. Relation between cancer cellularity and apparent diffusion coeffi cient values using diffusion-weighted magnetic resonance imaging in breast cancer. Radiat Med 2008; 26:222-226.

53. Bogner W, Gruber S, Pinker K, Grabner G, Stadlbauer A, Weber M, Moser E, Helbich TH, Trattnig S. Diffusion-weighted MR for Differentiation of Breast Lesions at 3.0 T: How Does Selection of Diffusion Protocols Affect Diagnosis? Radiology 2009; 253: 341-351.

54. Woodhams R, Kakita S, Hata H, Iwabuchi K, Kuranami M, Gautam S, Hatabu H, Kan H, Mountford C. Identifi cation of Residual Breast Carcinoma Following Neoadjuvant Chemotherapy: Diffusion -weighted Imaging - Comparison with Contrast-enhanced MR Imaging and Pathologic Findings. Radiology 2010; 254: 358-366.

55. Pereira FPA, Martins G, Figueiredo E, Domingues MNA, Domingues RC, da Fonseca LMB. The use of diffusion-weighted magnetic resonance imaging in the differentiation between benign and malignant breast lesions. Radiologia Brasileira 2009; 42: 283 - 288.

Acknowledgements: This work was supported by the project "CENTER OF EXCELLENCY FOR RESEARCH IN PERSONALIZED THERAPY (CEVYPET)“, code: 26220120053, co - financed from EU sources and European Regional Development Fund. The autors are grateful to Dr. N.A.Yeboah for critical reading of the manuscript.

Received: August, 24, 2011

Accepted: December, 5, 2011 